https://doi.org/10.30910/turkjans.775861

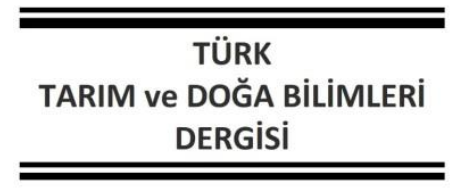

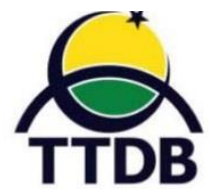

www.dergipark.gov.tr/turkjans

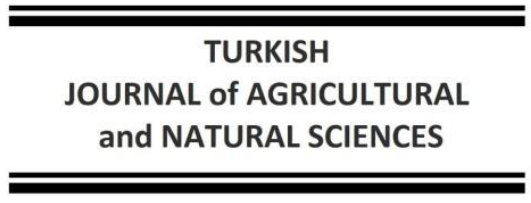

Araştırma Makalesi

\title{
Süs Lahanasının (Brassica oleracea L. var. Acephala) Yozgat Ekolojik Koşullarına Adaptasyonu
}

\author{
Tuğba KILIÇ ${ }^{1 *}$, Selin TEMiZEL ${ }^{2}$, YAŞAR KARADAĞ ${ }^{3}$ \\ ${ }^{1}$ Yozgat Bozok Üniversitesi, Ziraat Fakültesi, Bahçe Bitkileri Bölümü, Yozgat \\ ${ }^{2}$ Yozgat Bozok Üniversitesi, Ziraat Fakültesi, Peyzaj Mimarlığı Bölümü, Yozgat \\ ${ }^{3}$ Muş Alparslan Üniversitesi, Uygulamalı Bilimler Fakültesi, Tarla Bitkileri Bölümü, Muş \\ *Sorumlu Yazar: tugba-klc@hotmail.com
}

\section{Geliş Tarihi: 30.07.2020 Düzeltme Geliş Tarihi: 05.10.2020 Kabul Tarihi: 08.10.2020}

Öz

Bu araştırma, bazı hibrit süs lahanası (Brassica oleracea L. var. Acephala) çeşitlerinin Yozgat illi ekolojik koşullarına adaptasyon kabiliyetini belirlemek amacıyla yürütülmüştür. Bitkisel materyal olarak dört farklı hibrit süs lahanası çeşidi ( $F_{1}$ Pigeon White, $F_{1}$ Pigeon Red, $F_{1}$ Kamome White ve $F_{1}$ Kamome Red) kullanılmış, çeşitlere ait fideler iki vejetasyon dönemi boyunca deneme arazisindeki masuralara dikilmişlerdir. Denemede yaprak sayısı, bitki çapı, bitki boyu, merkez renklilik çapı, merkez yaprak rengi, nispi antosiyanin miktarı ve klorofil içeriği parametreleri incelenmiş; yaprak sayısı, merkez renklilik çapı, merkez yaprak rengi ve klorofil içeriği bakımından çeşit ortalamaları arasındaki farklılı̆ın istatistiki açıdan önem taşıdığı belirlenmiştir. Yaprak sayısı ile merkez renklilik çapı bakımından en yüksek değerler; $F_{1}$ Kamome White (20.53 adet / $18.47 \mathrm{~cm}$ ) ve $F_{1}$ Pigeon White $\left(20.37\right.$ adet / $18.17 \mathrm{~cm}$ ) çeşitlerinden elde edilmiş olup, $\mathrm{F}_{1}$ Kamome White çeşidi, en az yaprak sayısı ile en az merkez renklilik çapına sahip olan $F_{1}$ Pigeon Red çeşidinden yalnız 1.30 adet daha fazla yaprak ve $1.80 \mathrm{~cm}$ daha fazla renkli çap oluşturmuştur. En fazla klorofil içeriği ise, merkez yaprak rengini ifade eden 'a' değerinin (yeşillik-kırmızılık oranı) en yüksek olduğu $F_{1}$ Kamome Red $\left(65.96 \mu \mathrm{mol} \mathrm{m}^{-2}\right.$ ) çeşidinde saptanmıştır. Bununla birlikte, kıvırcık yapraklı çeşitlerin ( $F_{1}$ Kamome serisi) düz yapraklı çeşitlere ( $F_{1}$ Pigeon serisi) oranla kar yükünden daha fazla etkilendikleri ve görsel kalitelerini kaybettikleri gözlemlenmiştir. Araştırmada elde edilen bulgulara göre, tüm çeşitlerin Yozgat ili ekolojisinde yetiştirilebileceği, ancak bitkisel tasarım çalışmalarında kar yükü fazla olan bölgelerde düz yapraklı çeşitlerin öncelikli olarak tercih edilmesi gerektiği sonucuna varılmıştır.

Anahtar kelimeler: Adaptasyon, bitkisel tasarım, peyzaj, süs lahanası, Yozgat

\section{Adaptation of Ornamental Kale (Brassica oleracea L. var. Acephala) Under Yozgat Ecological Conditions}

\begin{abstract}
The research was conducted to determine the adaptation ability of some hybrid ornamental kale (Brassica oleracea L. var. Acephala) varieties under the ecological conditions of Yozgat Province. Four varieties of hybrid ornamental kale ( $F_{1}$ Pigeon White, $F_{1}$ Pigeon Red, $F_{1}$ Kamome White and $F_{1}$ Kamome Red) were used as a plant material. At the end of the experiment, leaf number, plant diameter, plant height, diameter of center color, center leaf color, amount of anthocyanin and chlorophyll content parameters were examined and it was determined that the difference between varieties was statistically significant in terms of leaf number, center color diameter, center leaf color and chlorophyll content parameters. The highest leaf number and diameter of center color was obtained from $F_{1}$ Kamome White and $F_{1}$ Pigeon White. $F_{1}$ Kamome White has only 1.30 more leaves and $1.80 \mathrm{~cm}$ more color diameter than $\mathrm{F}_{1}$ Pigeon Red variety. The highest chlorophyll content was found in $F_{1}$ Kamome Red $\left(65.96 \mu \mathrm{mol} \mathrm{m}{ }^{-2}\right)$, where a value (greenness-red ratio), which expresses the central leaf color, is highest. However, it has been determined that finged leaf varieties ( $F_{1}$ Kamome series) are more affected by snow load than the round leaf varieties ( $F_{1}$ Pigeon series). Finged leaf varieties lost their visual quality because of snow load. As a result of, it was concluded that all the cultivars used in the experiment can
\end{abstract}


be grown in the ecology of Yozgat Province, but round leaf varieties should be preferred primarily in regions with high snow loads in plant design.

Key words: Adaptation, plant design, landscape, ornamental kale, Yozgat

\section{Giriş}

Brassicaceae familyasında yer alan süs lahanası (Brassica oleracea var. Acephala), kesme çiçek, saksı ve peyzaj bitkisi olarak değerlendirilen iki yıllık otsu bir bitkidir (Kishimoto ve ark., 2014). Beyazdan, sarı, pembe, kırmızı veya mor renge kadar değişen renkte düz, kıvırcık veya ince saçaklı şekle sahip yaprakları (Hatipoğlu ve Gülgün, 1999; Carter, 2003; Zhu ve ark., 2017) yanında, düşük sıcaklığa dayanabilme kabiliyetine bağlı olarak sonbahar sonundan erken ilkbahara kadar sağlamış olduğu görsel kalite ile de yüksek ticari değere sahiptir (Ren ve ark., 2019; Weishu ve ark., 2019). Nitekim kış aylarında; park, bahçe, kavşak, orta refüj ve çiçek parterleri başta olmak üzere birçok alanın bitkisel tasarımında kullanılmaktadır (Carter, 2003).

Bitkisel tasarım çalışmalarında kullanılacak süs bitkilerinin morfolojik özellikleri ile intiyaç duydukları ekolojik koşulların mutlaka bilinmesi gerekmektedir. Her ne kadar kullanılan bitki tür ya da çeşidi renk, tekstür ve form özellikleri gibi birçok açıdan planlanan tasarıma uygunluk gösterse de bu bitkilerin adaptasyon kabiliyetine bağlı olarak çiçekli ya da yapraklı kalma süreleri gibi görsel kaliteyi doğrudan etkileyecek özellikleri ekolojiden ekolojiye farklılık göstermektedir. Diğer bir ifadeyle, bitkilerin ekolojik koşullara adaptasyonu, fonksiyonel ve estetik işlevlerini tam olarak yerine getirmelerinde en önemli faktördür. Dolayısıyla, tasarım çalışmalarında kullanılacak bitkilerin dendrolojik ve fenolojik özelliklerinin farklı ekolojik koşullar göz önünde bulundurularak değerlendirilmesi, tasarımın amacına yönelik istenilen etkiyi oluşturmada oldukça önem arz etmektedir (Aslanboğa ve ark. 1992'den aktaran Onat, 2012; Yazici, 2017; Atabeyoğlu ve Bilge, 2019; Kösa, 2019).

Sert kışların hüküm sürdüğü Yozgat il'inde, adaptasyon kuşağına uygun olup, tasarım çalışmalarında değerlendirilebilecek süs bitkisi çeşitliliği azdır. Özellikle canlı renkleri ve dikkat çekici formları ile bitkisel tasarımın karakterini önemli ölçüde belirleyen mevsimlik çiçeklerin kullanımı oldukça sınırlıdır. Bu durum, bitkisel tasarımın etkinliğini azaltmakta, görsel ve fonksiyonel mekânların oluşturulmasına da engel teşkil etmektedir. Tasarım çalışmalarında kullanılan süs bitkisi çeşitliliğinin az olması yanında, Yozgat Il'inde alternatif bitkilerin araştırılması üzerine yapılmış herhangi bir bilimsel çalışmaya da rastlanmamıştır. Dolayısıyla, Yozgat il'inde bitkisel tasarım çalışmalarında kullanılabilecek alternatif bitkilerin belirlenmesine yönelik adaptasyon çalışmalarına fazlasıyla intiyaç duyulmaktadır. Bu çalışma ile, bitkisel tasarımın oldukça önemli bir parçası olan mevsimlik çiçeklerden süs lahanasının, Yozgat illi ekolojik koşullarına adaptasyonu ve tasarım amaçlı kullanılabilirliği araştırılmıştır.

\section{Materyal ve Metot}

Araştırma, Yozgat ili Sorgun ilçesinde bulunan Yozgat Bozok Üniversitesi Ziraat Fakültesi Gedikhasanlı Araştırma ve Uygulama Merkezi'ne ait deneme arazisinde iki yıl süre ile (2017-2018 ve 2018-2019 vejetasyon dönemi) yürütülmüştür. Araziye ait uzun yıllar (2000-2019) aylık ortalama iklim verilerine göre, deneme alanının ortalama sıcaklık değeri 10.3 으, toplam yağış miktarı 433.9 $\mathrm{mm}$ ve nispi nem oranı ise \%65.9'dur. Araştırmanın yürütüldüğü 2017-2018 ve 2018-2019 yılları ekimmart aylarına ait ortalama sıcaklık, toplam yağış ve nispi nem değerleri ise sırasıyla; 5.5-4.63으, 241.8$251.0 \mathrm{~mm}$ ve \%72.18-72.31'dir. Denemenin yürütüldüğü her iki vejetasyon dönemine ait kar örtülü gün sayısı 2017-2018 vejetasyon dönemi için 30 gün (Kasım-Mart), 2018-2019 vejetasyon dönemi için ise 46 gündür (Aralık-Mart). Deneme alanının aylık ortalama iklim verileri, Çizelge 1'de verilmiştir.

Deneme alanına ait toprak özelliklerinin belirlenmesi amacıyla, 0-30 cm derinlikten alınan toprak örnekleri, Biyotar Toprak ve Bitki Analiz Laboratuvarında analiz edilmiştir. Analiz sonuçlarına göre, toprak tekstürünün kumlu-killitınlı, organik madde düzeyinin az (\%1.0) ve kireç içeriğinin ise orta (\%5.36) derecede olduğu saptanmıştır. Ayrıca, deneme toprağının 0.714 $\mathrm{dS} / \mathrm{m}$ elektriksel iletkenlik değeri ile tuzsuz ve 7.91 $\mathrm{pH}$ değeri ile de hafif alkali özellik gösterdiği belirlenmiştir (Çizelge 2).

Araştırmada bitkisel materyal olarak; $F_{1}$ Pigeon Red, $F_{1}$ Pigeon White, $F_{1}$ Kamome Red ve $F_{1}$ Kamome White olmak üzere farklı renk ve yaprak şekline sahip dört adet ticari hibrit süs lahanası (Brassica oleracea L. var. Acephala) çeşidi kullanılmıştır. Çeşitlere ait tohumlar 'Takii' firmasından temin edilmiş olup, $F_{1}$ Pigeon serisi çeşitler düz, $F_{1}$ Kamome serisi çeşitler ise kıvırcık yapraklara sahiptir. $F_{1}$ Pigeon Red ve $F_{1}$ Kamome Red çeşitleri kırmızı, $F_{1}$ Pigeon White ve $F_{1}$ Kamome White çeşitleri ise beyaz renklidir. 
Çizelge 1. Sorgun ilçesi aylık ortalama ve uzun yıllar ortalamasına ait bazı iklim verileri (Anonim 2020).

\begin{tabular}{|c|c|c|c|c|c|c|c|c|c|c|c|c|c|}
\hline Yıl/Ay & 1 & 2 & 3 & 4 & 5 & 6 & 7 & 8 & 9 & 10 & 11 & 12 & $\begin{array}{l}\text { Ort/ } \\
\text { Top }\end{array}$ \\
\hline \multicolumn{14}{|c|}{ Aylık Ortalama Sıcaklık (ㅇ) } \\
\hline 2017 & -3.3 & -0.2 & 5.9 & 9.3 & 13.7 & 18.3 & 22.2 & 22.4 & 20.5 & 10.5 & 4.8 & 3.0 & 10.56 \\
\hline 2018 & 0.9 & 5.2 & 8.6 & 12.3 & 15.8 & 19.2 & 22.2 & 21.8 & 18.0 & 12.8 & 6.8 & 2.0 & 12.31 \\
\hline 2019 & -0.8 & 2.7 & 4.3 & 8.3 & 16.0 & 20.0 & 19.5 & 20.4 & 16.7 & 14.2 & 7.0 & 2.9 & 10.93 \\
\hline $\begin{array}{l}2000- \\
2019\end{array}$ & -1.3 & 0.5 & 5.0 & 9.8 & 14.3 & 18.3 & 21.3 & 21.5 & 17.1 & 11.7 & 5.4 & 0.5 & 10.3 \\
\hline \multicolumn{14}{|c|}{ Aylık Toplam Yağış (mm) } \\
\hline 2017 & 43.6 & 4.4 & 40.0 & 39.8 & 10.2 & 31.6 & 0.0 & 2.8 & 1.2 & 25.4 & 76.0 & 23.2 & 298.2 \\
\hline 2018 & 35.8 & 20.6 & 60.8 & 3.4 & 71.2 & 57.6 & 4.0 & 0.0 & 22.0 & 36.8 & 17.0 & 81.6 & 410.8 \\
\hline 2019 & 70.2 & 30.2 & 15.2 & 26.2 & 22.2 & 79.8 & 14.4 & 8.2 & 0.0 & 7.0 & 21.8 & 49.2 & 344.4 \\
\hline $\begin{array}{l}2000- \\
2019\end{array}$ & 52.3 & 45.7 & 42.9 & 47.4 & 47.8 & 26.2 & 15.0 & 9.2 & 29.8 & 22.7 & 46.5 & 48.4 & 433.9 \\
\hline \multicolumn{14}{|c|}{ Aylık Ortalama Nispi Nem (\%) } \\
\hline 2017 & 80.9 & 71.3 & 64.6 & 55.6 & 63.3 & 63.1 & 47.0 & 56.2 & 41.0 & 57.8 & 75.4 & 81.4 & 63.13 \\
\hline 2018 & 80.6 & 70.4 & 67.5 & 50.1 & 68.2 & 60.0 & 54.0 & 49.6 & 53.3 & 65.6 & 70.2 & 82.6 & 64.34 \\
\hline 2019 & 80.3 & 73.2 & 62.0 & 66.6 & 56.7 & 63.0 & 56.2 & 58.1 & 54.4 & 58.3 & 59.6 & 79.6 & 64.00 \\
\hline $\begin{array}{l}2000- \\
2019\end{array}$ & 79.5 & 74.8 & 67.4 & 62.6 & 63.2 & 60.6 & 55.7 & 55.6 & 56.3 & 65.0 & 70.6 & 79.8 & 65.9 \\
\hline
\end{tabular}

Çizelge 2. Deneme alanına ait toprağın bazı fiziksel ve kimyasal özellikleri

\begin{tabular}{|c|c|c|}
\hline Parametre & Analiz Sonucu & Değerlendirme \\
\hline Azot (N-\%) & 0.05 & $A z$ \\
\hline Fosfor $\left(\mathrm{P}_{2} \mathrm{O}_{5}-\mathrm{kg} / \mathrm{da}\right)$ & 3.03 & $\mathrm{Az}$ \\
\hline Potasyum $\left(\mathrm{K}_{2} \mathrm{O}-\mathrm{kg} / \mathrm{da}\right)$ & 64.83 & Yeterli \\
\hline Kalsiyum (Ca-ppm) & 75.61 & Fazla \\
\hline Magnezyum (Mg-ppm) & 166.6 & Yeterli \\
\hline Sodyum (Na-ppm) & 15.12 & - \\
\hline Demir (Fe-ppm) & 2.05 & $\mathrm{Az}$ \\
\hline Bakır (Cu-ppm) & 0.42 & Yeterli \\
\hline Çinko (Zn-ppm) & 0.29 & Çok Az \\
\hline Mangan (Mn-ppm) & 4.44 & Fazla \\
\hline Bor (B-ppm) & $<0.005$ & - \\
\hline Organik Madde (\%) & 1.00 & $\mathrm{Az}$ \\
\hline Bünye (kil/silt/kum-\%) & 29.87 / 8.94 / 61.19 & Kumlu Killi Tın \\
\hline pH & 7.91 & Hafif Alkali \\
\hline $\mathrm{EC}(\mathrm{dS} / \mathrm{m})$ & 0.714 & - \\
\hline Tuzluluk oranı (\%) & 0.0207 & Tuzsuz \\
\hline Kireç (\%) & 5.36 & Orta \\
\hline
\end{tabular}

Çeşitlere ait tohumlar temmuz ayında, standardize torf materyali ile doldurulmuş (Klasmann TS1) viyollere, her bir bölmeye bir adet tohum gelecek şekilde ekilmiştir. Örtüaltı koşullarında yetiştirilen fideler 4-5 gerçek yapraklı aşamaya geldiğinde, yine standardize torf materyali ile doldurulmuş 5 litrelik saksılara şaşırtılmış ve 20 gün ara ile iki kez NPK 20:20:20+ME kimyasal gübre (2-3 $\mathrm{kg} / \mathrm{da})$ kullanılarak fertigasyon şeklinde gübrelenmiştir.
Merkez yapraklarda çeşide özgü renklenmenin görüldüğü eylül ayından itibaren gübreleme işlemine son verilmiş ve toprak üst yüzeyinin kuruma durumuna göre sulama işlemine devam edilmiştir. Standart kültürel uygulamalara devam edilirken, yaprak güvesine karşı $50 \mathrm{~g} / \mathrm{L}$ lambdacyhalothrin etken maddeli insektisit ile mücadele yapılmıştır. Dikime hazır halde bulunan fideler ekim ayında, önceden derin toprak işleme ardından yüzlek toprak işlemesi yapılan ve dekara 1 ton 
yanmış ahır gübresi verilen deneme arazisinde masuralar üzerine $30 \times 30 \mathrm{~cm}$ aralık mesafeyle dikilmişlerdir. Sulama, damla sulama yöntemi ile yapılmış olup, kasım ayında sulama işlemine son verilmiştir. Arazi koşullarında herhangi bir gübre uygulaması yapılmamıştır.

Deneme, bitkiler sapa kalktığında ya da yaprakların \%50'sinde görsel kalite kaybı (kahverengileşme ve solma) gözlendiği zaman sonlandırılmıştır. Süs lahanası bitkilerinde görsel kalitenin ortaya konulabilmesi ve çeşitlerin adaptasyon kabiliyetlerinin belirlenebilmesi amacıyla, yaprak sayısı (adet), bitki çapı (cm), bitki boyu $(\mathrm{cm})$, merkez renklilik çapı $(\mathrm{cm})$, merkez yaprak rengi (Konica minolta CR-400/410-CIE $\left.\mathrm{L}^{*} \mathrm{a}^{*} \mathrm{~b}^{*}\right)$ renkli merkez yapraklarda nispi antosiyanin miktarı (Opti Science ACM-200 Plus) ve dış yeşil yapraklarda klorofil içeriği (Konica Minolta SPAD-502 Plus) ölçümleri yapılmıştır. Deneme, Tesadüf Blokları Deneme Desenine göre 3 tekerrürlü ve her tekerrürde 10 bitki olacak şekilde tam şansa bağlı olarak kurulmuştur. Elde edilen verilerin değerlendirilmesinde SPSS 20.0 istatistik paket programı kullanılmış; ortalamalar arasındaki farklılık, Duncan Çoklu Karşılaştırma Testi ve Bağımsız Örneklem T Testi $(p \leq 0.05)$ ile değerlendirilmiştir.

\section{Bulgular ve Tartışma}

Yozgat ili ekolojik koşullarında dört farklı hibrit süs lahanası çeşidi ile iki vejetasyon dönemi boyunca yürütülen çalışmada incelenen özelliklerden elde edilen veriler, hem her yıl için ayrı ayrı hem de her iki vejetasyon döneminin ortalaması dikkate alınarak varyans analizine tabi tutulmuştur. Yıllar bazında 'çeşit', 'yıl' ve 'çeşit x yıl' faktörleri üzerine yapılan varyans analizi sonuçlarına göre, klorofil içeriği özelliğinin ' $y ı l ~ x$ çeşit' interaksiyonu, yaprak sayısı ve merkez renklilik çapı özelliklerinin 'yıl' ve 'çeşit' faktörleri; merkez yaprak rengi ( $L, a, b$ değerleri) özelliğinin ise 'çeşit' faktörü bakımından istatistiksel anlamda önemli bir farklılık gösterdiği belirlenmiştir. Bitki çapı, bitki boyu ve nispi antosiyanin miktarı bakımından ise 'yıl' ya da 'çeşit' faktörlerinin istatistiksel anlamda önemli bir etki göstermediği tespit edilmiştir. Her iki yıla ait verilerin ortalaması alınarak yapılan varyans analizi sonuçları değerlendirildiğinde; bitki boyu, bitki çapı ve nispi antosiyanin miktarı bakımından istatistiksel anlamda bir farklılık bulunmazken, incelenen diğer özellikler bakımından 'çeşit' faktörünün istatistiki açıdan önem arz ettiği belirlenmiştir.

Yaprak Sayısı: Hibrit süs lahanası çeşitlerine ait ortalama yaprak sayıları Çizelge 1'de verilmiştir. Çizelge 3'te görüleceği üzere, 2017-2018 vejetasyon döneminde en fazla yaprak, $F_{1}$ Kamome White (19.73 adet) çeşidinde belirlenmiş olmakla birlikte bu çeşit, $F_{1}$ Pigeon White (19.63 adet) çeşidi ile aynı istatistik grup içerisinde yer almıştır. 20182019 vejetasyon döneminde de en fazla yaprak $F_{1}$ Kamome White (20.73 adet) çeşidinde saptanmış olup bu çeşit, $F_{1}$ Pigeon White (20.57 adet) ve $F_{1}$ Kamome Red (20.43 adet) çeşitleri ile aynı istatistik grup içerisinde yer almıştır.

Çeşitlerin her iki vejetasyon dönemindeki ortalama performansları değerlendirildiğinde, $F_{1}$ Kamome White (20.53 adet) ile $F_{1}$ Pigeon White (20.37 adet) çeşitlerinin, $F_{1}$ Kamome Red (19.87 adet) ve $F_{1}$ Pigeon Red (19.23 adet) çeşitlerinden daha fazla yaprak sayısına sahip olduğu belirlenmiştir. Yaprak sayısı en az olan $F_{1}$ Pigeon Red çeşidi, yaprak sayısı en fazla olan $F_{1}$ Kamome White çeşidinden yalnız 1.30 adet daha az yaprağa sahiptir. 2018-2019 vejetasyon döneminde bir önceki yıla göre ortalama 1.10 adet daha fazla yaprak elde edilmiştir (Çizelge 3 ).

Çizelge 3. Hibrit süs lahanası çeşitlerinin vejetasyon dönemlerine ait ortalama yaprak sayıları.

\begin{tabular}{|l|c|c|c|}
\hline \multirow{2}{*}{\multicolumn{1}{|c|}{ Çeşit }} & \multicolumn{3}{|c|}{ Yaprak Sayısı (adet) } \\
\cline { 2 - 4 } & $\mathbf{2 0 1 7 - 2 0 1 8}$ & $\mathbf{2 0 1 8 - 2 0 1 9}$ & Yıl Ortalaması \\
\hline F $_{1}$ Pigeon Red & $18.70 \mathrm{~b}$ & $19.50 \mathrm{~b}$ & $19.23 \mathrm{C}$ \\
\hline F $_{1}$ Pigeon White & $19.63 \mathrm{a}$ & $20.57 \mathrm{a}$ & $20.37 \mathrm{~A}$ \\
\hline F $_{1}$ Kamome Red & $18.80 \mathrm{~b}$ & $20.43 \mathrm{a}$ & $19.87 \mathrm{~B}$ \\
\hline F $_{1}$ Kamome White & $19.73 \mathrm{a}$ & $20.73 \mathrm{a}$ & $20.53 \mathrm{~A}$ \\
\hline Çeşit Ortalaması & $19.21 \mathrm{~B}$ & $20.30 \mathrm{~A}$ & - \\
\hline
\end{tabular}

*Aynı harfler ile gösterilen ortalamalar arasındaki farklııı $p \leq 0.05$ düzeyinde önemsizdir.

Çalışmada kullanılan çeşitler arasında yaprak sayısı genel olarak 18.70 adet ile 20.73 adet arasında değişmiş olmakla birlikte, Muntean ve ark. (2012) tarafından 9 farklı hibrit süs lahanası çeşidi ile yapılan bir çalışmada yaprak sayısı, 10.48 adet ile 26.33 adet arasında; Köksal ve ark. (2016) tarafından 3 farklı hibrit süs lahanası çeşidi ile yapılan bir çalışmada, 21.0 adet ile 34.0 adet arasında ve Akın ve Kahraman (2018) tarafından süs lahanası genotipleri ile yapılan bir çalışmada ise 27.83 adet ile 40.42 adet arasında değişmiştir. Yaprak sayısı bakımından çalışmalar arasında bir 
varyasyon görülmekle birlikte, bu varyasyonun çeşit, yetiştirme ortamı ve iklim koşulları arasındaki farklılıklardan kaynaklanabileceği düşünülmektedir. Nitekim yaprak sayısı özelliğinin, genotip ve iklim faktörlerinden oldukça etkilendiği ve ekolojik koşullara adaptasyonun bir ölçütü olarak değerlendirildiği bildirilmiştir (El-Soda ve ark., 2014; Li ve ark., 2016). Bunun yanında, çalışmalarda yaprak sayısının belirlenmesinde kullanılan yöntemlerdeki farklılık, yaprak sayısında görülen varyasyonun bir diğer nedeni olabilir. Çalışmamızda henüz olgunluğa ulaşmamış merkez yapraklarda sayım yapılmamış olup, Akın ve Kahraman (2018) tarafından bitki merkezinde yer alan genç yapraklarda da sayım yapılmış ve toplam yaprak sayısı olarak ifade edilmiştir.

Çalışmamızda 2017-2018 vejetasyon döneminde elde edilen yaprak sayısı, 2018-2019 vejetasyon döneminde elde edilen yaprak sayısına göre, çeşit bazında, 0.80 adet ile 1.60 adet arasında artış göstermiştir. Söz konusu bu artış, ikinci vejetasyon döneminde 0.8 o C'lik sıcaklık düşüşü ve $9.2 \mathrm{~mm}$ kadar artan yağışa bağlı olarak bitki su kullanımının artmasından ileri gelmiş olabilir. Bununla birlikte, her ne kadar yaprak sayısı çeşitler arasında istatistiki açıdan önem arz etmiş olsa da 1.60 adet olarak belirlenen yaprak sayısı farkının bitkisel tasarım açısından büyük bir değişikliğe neden olmayacağı düşünülmektedir.

Bitki boyu ve bitki çapı: Hibrit süs lahanası çeşitlerine ait ortalama bitki boyu ve bitki çapı değerleri Çizelge 4'te verilmiş olmakla birlikte, her iki özellik bakımından da çeşitlere ait ortalamalar arasındaki farklılık istatistiksel anlamda önemli bulunmamıştır. Ancak rakamsal olarak gerek vejetasyon dönemlerine gerekse yıl ortalamalarına göre bir değerlendirme yapıldığında; en uzun bitki boyu $F_{1}$ Kamome Red (yıl ort: $11.18 \mathrm{~cm}$ ), en fazla bitki çapı ise $F_{1}$ Kamome White (yıl ort: $24.50 \mathrm{~cm}$ ) çeşidinde belirlenmiştir.

Çizelge 4. Hibrit süs lahanası çeşitlerinin vejetasyon dönemlerine ait ortalama bitki boyu ve bitki çapı değerleri.

\begin{tabular}{|l|c|c|c|c|c|c|}
\hline \multirow{2}{*}{\multicolumn{1}{|c}{ Çeşit }} & \multicolumn{3}{|c|}{ Bitki Boyu (cm) $^{*}$} & \multicolumn{3}{c|}{ Bitki Çapı (cm) $^{*}$} \\
\cline { 2 - 7 } & $\mathbf{2 0 1 7 - 2 0 1 8}$ & $\mathbf{2 0 1 8 - 2 0 1 9}$ & YIl Ort. & $\mathbf{2 0 1 7 - 2 0 1 8}$ & $\mathbf{2 0 1 8 - 2 0 1 9}$ & YIl Ort. \\
\hline F1 Pigeon Red & 10.96 & 11.20 & 11.08 & 21.40 & 20.40 & 21.17 \\
\hline F1 Pigeon White & 11.10 & 10.77 & 10.94 & 23.73 & 21.63 & 22.90 \\
\hline F $_{1}$ Kamome Red & 11.30 & 11.07 & 11.19 & 23.70 & 21.60 & 22.83 \\
\hline F $_{1}$ Kamome White & 10.90 & 11.07 & 10.99 & 25.50 & 23.03 & 24.50 \\
\hline Çeşit Ortalaması & 11.07 & 11.03 & - & 23.58 & 21.67 & - \\
\hline
\end{tabular}

*Ortalamalar arasındaki farklılık $\mathrm{p} \leq 0.05$ düzeyinde önemsizdir.

Çalışmada, çeşitlere ait bitki boyları genel olarak $10.77 \mathrm{~cm}$ ile $11.30 \mathrm{~cm}$; bitki çapları ise 21.40 $\mathrm{cm}$ ile $25.50 \mathrm{~cm}$ arasında değişiklik göstermiş olmakla birlikte, Ağar (2015) tarafından saksı kültüründe yetiştirilen iki farklı hibrit süs lahanası çeşidinde bitki boyunun $6.60 \mathrm{~cm}$ ile $12.20 \mathrm{~cm}$ arasında, Akın (2019) tarafından süs lahanası genotiplerinin saksı kültüründe yetiştirildiği bir diğer çalışmada bitki boyunun $11.58 \mathrm{~cm}$ ile 13.83 $\mathrm{cm}$, bitki çapının ise $14.75 \mathrm{~cm}$ ile $18.08 \mathrm{~cm}$ arasında ve Köksal ve ark. (2016) tarafından iki farklı hibrit süs lahanası çeşidinin plastik torbalarda örtü altında yetiştirildiği çalışmada bitki boyunun 8.10 $\mathrm{cm}$ ile $12.50 \mathrm{~cm}$, bitki çapının ise $14.0 \mathrm{~cm}$ ile 21.6 $\mathrm{cm}$ arasında değişiklik gösterdiği saptanmıştır. Bitki boyu ve bitki çapı bakımından çalışmalar arasında görülen bu farklılıkların, yetiştirme tekniği ve yetiştirme koşulları ile genotip farklılıklarına bağıı olarak ortaya çıkabileceği düşünülmektedir. Nitekim bitki boyu ve bitki çapı özelliklerinin, aynı tür ve/veya çeşidin örtü altı ya da açıkta yetiştirilmesine göre veya uygulanan kültürel işlemlerdeki farklılıklara bağlı olarak değişiklik gösterebileceği bildirilmektedir (Muntean ve ark., 2012; Ulukapı ve Şener, 2018). Çalışmamızda aynı zamanda bitki boyu ve bitki çapı bakımından ne çeşit ne de vejetasyon dönemleri arasında bir farklılık bulunmamıştır. Bu durum, kullanılan çeşitlerin benzer yetiştirme koşullarına ihtiyaç duymasından ileri gelebilir ya da her iki vejetasyon döneminde de görülen iklim koşullarının bitki boyu ve bitki çapını belirgin düzeyde etkileyebilecek bir farklılık göstermemesinden kaynaklanabilir. Nitekim bitkilerin adaptasyonda, çevre şartlarında meydana gelen farklılıklara karşı fenotipik değişiklikler ile tepki gösterdikleri bilinmektedir (Taş, 2000).

Merkez renklilik çapı: Hibrit süs lahanası çeşitlerine ait ortalama merkez renklilik çapı değerleri Çizelge 5'te verilmiştir. Çizelge 5'te görüleceği üzere, 2017-2018 vejetasyon döneminde en fazla renkli çap oluşturan çeşit, $F_{1}$ Kamome White $(19.30 \mathrm{~cm})$ olmuştur. Ancak bu çeşit ile $F_{1}$ Pigeon White $(18.77 \mathrm{~cm})$ çeşidine ait ortalamalar arasındaki farklılık, istatistiki açıdan önemli bulunmamıştır. En az renkli çap oluşturan çeşit, $F_{1}$ Pigeon Red $(16.83 \mathrm{~cm})$ olmuştur. Bu çeşit, $F_{1}$ Kamome White çeşidine göre $2.47 \mathrm{~cm}$ daha küçük renkli merkez çapı oluşturmuştur.

Çeşitlerin 2018-2019 vejetasyon dönemine ait merkez renklilik çapı değerleri incelendiğinde, en fazla renkli çap oluşturan çeşidin $F_{1}$ Pigeon White $(17.17 \mathrm{~cm})$ olduğu ve $F_{1}$ Kamome White 
$(17.10 \mathrm{~cm})$ çeşidi ile aynı istatistik grup içerisinde yer aldığı belirlenmiştir. En az merkez renklilik çapı ise $F_{1}$ Kamome Red $(15.77 \mathrm{~cm})$ çeşidinde tespit edilmiştir. Çeşitlerin her iki vejetasyon dönemine ait ortalama değerleri incelendiğinde, 2018-2019 vejetasyon dönemine benzer şekilde, $F_{1}$ Kamome White $(18.47 \mathrm{~cm})$ ile $F_{1}$ Pigeon White $(18.17 \mathrm{~cm})$ çeşitlerinin, $F_{1}$ Kamome Red $(16.93 \mathrm{~cm})$ ve $F_{1}$ Pigeon Red (16.67 adet) çeşitlerinden daha fazla renkli merkez çapına sahip olduğu saptanmıştır. Bununla birlikte, 2017-2018 vejetasyon döneminde, çeşitlerin bir sonraki yıla göre ortalama $1.61 \mathrm{~cm}$ daha fazla renkli çap oluşturduğu belirlenmiştir (Çizelge 5).

Çizelge 5. Hibrit süs lahanası çeşitlerinin vejetasyon dönemlerine ait ortalama merkez renklilik çapı değerleri.

\begin{tabular}{|l|c|c|c|}
\hline \multirow{2}{*}{\multicolumn{1}{c|}{ Çeşit }} & \multicolumn{3}{|c|}{ Merkez Renklilik Çapı (cm) } \\
\cline { 2 - 4 } & $\mathbf{2 0 1 7 - 2 0 1 8}$ & $\mathbf{2 0 1 8 - 2 0 1 9}$ & Yıl Ortalaması \\
\hline F1 Pigeon Red & $16.83 \mathrm{c}$ & $16.03 \mathrm{~b}$ & $16.67 \mathrm{~B}$ \\
\hline F1 Pigeon White & $18.77 \mathrm{ab}$ & $17.17 \mathrm{a}$ & $18.17 \mathrm{~A}$ \\
\hline F $_{1}$ Kamome Red & $17.63 \mathrm{bc}$ & $15.77 \mathrm{~b}$ & $16.93 \mathrm{~B}$ \\
\hline F1 Kamome White & $19.30 \mathrm{a}$ & $17.10 \mathrm{a}$ & $18.47 \mathrm{~A}$ \\
\hline Çeşit Ortalaması & $18.13 \mathrm{~A}$ & $16.52 \mathrm{~B}$ & - \\
\hline
\end{tabular}

*Aynı harfler ile gösterilen ortalamalar arasındaki farklııı $\mathrm{p} \leq 0.05$ düzeyinde önemsizdir.

Çalışmada kullanılan çeşitler arasında merkez renklilik çapı genel olarak $15.77 \mathrm{~cm}$ ile $19.30 \mathrm{~cm}$ arasında değişiklik göstermiştir. Köksal ve ark. (2016), iki farklı hibrit süs lahanasında merkez renklilik çapının $9.20 \mathrm{~cm}$ ile $14.90 \mathrm{~cm}$ arasında; Gibson ve ark. (2001), 26 farklı hibrit süs lahanasında ise $4.90 \mathrm{~cm}$ ile $16.60 \mathrm{~cm}$ arasında değiştiğini saptamıştır. Yapılan çalışma sonuçlarından görüleceği üzere, merkez renklilik çapı oldukça geniş bir varyasyon göstermiş olup, çalışmamızda elde edilen merkez renklilik çapı, diğer çalışmalarda elde edilen merkez renklilik çapına göre daha yüksek değerlere ulaşmıştır. Bu durum, kullanılan çeşitlerin farklılık göstermesine bağı olarak ortaya çıkabilir. Bununla birlikte, süs lahanası bitkilerinin yetiştirildiği bölgeler arasındaki sıcaklık farklılıkları da merkez renklilik çapları arasındaki değişimin bir nedeni olabilir. Süs lahanalarında yaprak renklenmesinin sıcaklık rejimlerinden oldukça etkilendiği, gece ve gündüz sıcaklık farkının yüksek olduğu lokasyonlarda daha iyi renklenme sağlandığı (Sikora ve Bodziarczyk, 2012) ve iyi bir yaprak renklenmesi için $10^{\circ} \mathrm{C}^{\prime} \mathrm{nin}$ altındaki gece sıcaklıklarına ihtiyaç duyulduğu bildirilmektedir (Bazzocchi ve Giorgioni, 2003). Bu çalışmanın yürütüldüğü deneme alanının da diğer her iki çalışmanın yürütüldüğü deneme alanından, artan rakıma bağlı olarak, daha yüksek gece ve gündüz sıcaklık farkına sahip olduğu düşünülmektedir (Anonim, 2020).

Merkez yaprak rengi ( $L, a, b$ değerleri): Hibrit süs lahanası çeşitlerinde renkli merkez yapraklara ait renk parametreleri olan $L$, $a$ ve $b$ değerleri Çizelge $6^{\prime} \mathrm{da}$ verilmiştir. Çizelge $6^{\prime} \mathrm{da}$ görüleceği üzere, parlaklığı ifade eden ' $L$ ' değeri, her iki vejetasyon döneminde de olmak üzere; $F_{1}$ Kamome White çeşidinde (2017-2018 yılı: 71.42, 2018-2019 yılı: 71.47) en yüksek değere ulaşmıştır. Yeşillik-kırmızılık oranını ifade eden 'a' değeri, $F_{1}$
Pigeon Red (2017-2018 yılı: 25.24, 2018-2019 yılı: 24.37) ve $F_{1}$ Kamome Red (2017-2018 yılı: 24.76, 2018-2019 yılı: 24.36), mavilik-sarılık oranını ifade eden ' $b$ ' değeri ise $F_{1}$ Kamome White (2017-2018 yılı: 12.56, 2018-2019 yılı: 12.74) ve $F_{1}$ Pigeon White (2017-2018 yılı: 11.75, 2018-2019 yılı: 11.88) çeşitlerinde en yüksek değeri vermiştir.

Çeşitlerin her iki vejetasyon dönemindeki ortalama performansları değerlendirildiğinde, en parlak yapraklara sahip çeşidin $\mathrm{F}_{1}$ Kamome White (71.45) olduğu belirlenmiştir. Yeşillik-kırmızılık oranı bakımından $F_{1}$ Pigeon Red (24.80) ve $F_{1}$ Kamome Red (24.56) en yüksek değerlere ulaşırken, mavilik-sarılık oranı bakımından $F_{1}$ Kamome White (12.65) çeşidinin en yüksek değere sahip olduğu saptanmıştır (Çizelge 6).

Çalışmada beyaz renkli hibrit çeşitlerde mavilik-sarılık oranı, kırmızı renkli hibrit çeşitlerde ise kırmızılık-yeşillik oranı en yüksek değeri vermiştir. Kırmızı renkli çeşitlerin, beyaz renkli çeşitlere göre daha yüksek miktarlarda antosiyanin pigmenti içermesi nedeniyle kırmızı-yeşillik oranını ifade eden ' $a$ ' değerinin pozitif olması beklenen bir sonuçtur. Zhu ve ark. (2017) tarafından süs lahanalarında antosiyanin içeriği ve renklenme üzerine yapılan bir çalışmada, renk pigmenti türlerine göre merkez yapraklardaki rengin değişiklik gösterdiği, antosiyanin ile birlikte klorofil ve karotenoid pigmenti oranlarının merkez yapraklardaki rengin belirlenmesinde rol oynadığı, beyaz renkli çeşitlerde antosiyanin pigmentine rastlanmadığı ifade edilmiştir. Bununla birlikte kırmızı hibrit çeşitler arasında kırmızılık-yeşillik oranı, beyaz çeşitler arasında ise mavilik-sarılık ora nı bakımından bir farklılık bulunmamıştır. Tüm çeşitler arasında yalnız parlaklık oranı bakımından bir farklılık söz konusu olup, beyaz renkli çeşitlerin daha parlak yapraklara sahip olduğu saptanmıştır. 
Çizelge 6. Hibrit süs lahanası çeşitlerinin vejetasyon dönemlerine ait $L$, a ve $b$ değerleri.

\begin{tabular}{|c|c|c|c|c|c|c|c|c|c|}
\hline \multirow{3}{*}{ Çeşit } & \multicolumn{9}{|c|}{ Merkez Yaprak Rengi (L, a, b) } \\
\hline & \multicolumn{3}{|c|}{ 2017-2018 } & \multicolumn{3}{|c|}{ 2018-2019 } & \multicolumn{3}{|c|}{ Yıl Ortalaması } \\
\hline & $\mathbf{L}$ & $\mathbf{a}$ & b & $\mathbf{L}$ & a & b & $\mathbf{L}$ & a & b \\
\hline$F_{1}$ Pigeon Red & $23.93 \mathrm{~d}$ & $25.24 \mathrm{a}$ & $-7.05 b$ & $23.96 \mathrm{~d}$ & $24.37 \mathrm{a}$ & $-6.80 b$ & $23.93 \mathrm{D}$ & $24.80 \mathrm{~A}$ & $-6.92 C$ \\
\hline$F_{1}$ Pigeon White & $68.59 \mathrm{~b}$ & $-0.28 b$ & $11.75 \mathrm{a}$ & $67.38 b$ & $-0,99 b$ & $11.88 \mathrm{a}$ & 67.98 B & $-0.19 \mathrm{~B}$ & $11.81 \mathrm{~B}$ \\
\hline$F_{1}$ Kamome Red & $26.06 \mathrm{c}$ & $24.76 \mathrm{a}$ & $-7.21 b$ & $25.62 \mathrm{c}$ & $24.36 \mathrm{a}$ & $-6.38 b$ & $25.84 \mathrm{C}$ & $24.56 \mathrm{~A}$ & $-6.79 \mathrm{C}$ \\
\hline $\begin{array}{l}F_{1} \text { Kamome } \\
\text { White }\end{array}$ & $71.42 \mathrm{a}$ & $-1.73 b$ & $12.56 \mathrm{a}$ & $71.47 \mathrm{a}$ & $-2.04 \mathrm{c}$ & $12.74 \mathrm{a}$ & $71.45 \mathrm{~A}$ & $-1.88 \mathrm{C}$ & $12.65 \mathrm{~A}$ \\
\hline $\begin{array}{l}\text { Çeşit } \\
\text { Ortalaması }\end{array}$ & 47.50 & 12.00 & 2.51 & 47.11 & 11.43 & 2.86 & & - & \\
\hline
\end{tabular}

*Aynı harfler ile gösterilen ortalamalar arasındaki farklııı $p \leq 0.05$ düzeyinde önemsizdir.

Kırmızı renkli çeşitlerde yaprak parlaklığının daha az olması, yaprakların koyu renkli olması ile ilişkili olabilir. Nitekim Keskin ve ark. (2017) tarafından da çilek bitkisinde koyu renkli yapraklarda parlaklık değerinin daha düşük olduğu bildirilmiştir. Çalışmada su içeriği yüksek olan yapraklarda parlaklık değerinin daha düşük olduğu ve yeşillik-kırmızılık oranı ile yaprak su içeriği arasında pozitif bir korelasyon olduğu saptanmıştır. Dolayısıyla, bu çalışmada da beyaz renkli çeşitlerde daha parlak yaprakların varlığı, yaprak su içeriğinin daha düşük olması ile ilişkili olabilir.
Nispi antosiyanin miktarı: Kırmızı renkli merkez yapraklara sahip hibrit süs lahanası çeşitlerine ait ortalama antosiyanin miktarları Çizelge 7'de verilmiştir. Çizelge 7'de de görüleceği üzere, nispi antosiyanin miktarı bakımından çeşitler ya da yıl ortalamaları arasındaki farklılıklar istatistiki açıdan önem arz etmese de rakamsal olarak bir değerlendirme yapıldığında; $F_{1}$ Kamome Red çeşidinin (79.12 ACl) $F_{1}$ Pigeon Red çeşidinden (73.05 ACl) ve 2018-2019 vejetasyon döneminin (79.26 ACl) 2017-2018 vejetasyon döneminden (72.90 ACl) daha fazla antosiyanin miktarına sahip olduğu saptanmıştır.

Çizelge 7. Hibrit süs lahanası çeşitlerinin vejetasyon dönemlerine ait nispi antosiyanin miktarları

\begin{tabular}{|l|c|c|c|}
\hline \multirow{2}{*}{\multicolumn{1}{c|}{ Çeşit }} & \multicolumn{3}{|c|}{ Nispi Antosiyanin Miktarı (ACI) } \\
\cline { 2 - 4 } & $\mathbf{2 0 1 7 - 2 0 1 8 *}$ & $\mathbf{2 0 1 8 - 2 0 1 9 *}$ & Yıl Ortalaması* \\
\hline F1 Pigeon Red & 70.95 & 75.15 & 73.05 \\
\hline F1 Kamome Red & 74.86 & 83.37 & 79.12 \\
\hline Çeşit Ortalaması & 72.90 & 79.26 & - \\
\hline
\end{tabular}

* Ortalamalar arasındaki farklılık $\mathrm{p} \leq 0.05$ düzeyinde önemsizdir.

Kırmızı renkli çeşitlerde yapılan ölçümler sonucunda belirlenen nispi antosiyanin miktarları incelendiğinde, çeşitlerin antosiyanin içerikleri arasında $6.07 \mathrm{ACl}$ değerinde bir farklılık olduğu görülmektedir. Süs lahanalarında merkez yapraklardaki kırmızı rengin antosiyanin miktarına bağlı olarak değişiklik gösterdiği düşünüldüğünde (Zhu ve ark., 2017), 6.07 ACl değerindeki farkın merkez yapraklarda (çeşitlerin ' $+a$ ' değerleri arasında 0.48 birimlik fark) önemli derecede bir renk değişimine neden olmadığı söylenebilir. Bununla birlikte, sıcaklığın antosiyanin birikimi üzerine etkili en önemli çevre faktörü olduğu düşünüldüğünde (Dela ve ark., 2003), antosiyanin miktarının vejetasyon dönemleri arasında istatistiki açıdan önemli bir farklılık göstermediği; 0.8 o C'lik sıcaklık değişiminin de antosiyanin miktarları arasında önemli bir farklılığa neden olmayabileceği düşünülmektedir.

Klorofil içeriği: Hibrit süs lahanası çeşitlerine ait ortalama klorofil içerikleri Çizelge $8^{\prime}$ de verilmiştir. Çizelge $8^{\prime}$ de görüleceği üzere, her iki vejetasyon döneminde de en yüksek klorofil içeriğine sahip çeşit $F_{1}$ Kamome Red olmuştur (2017-2018 yılı: $60.11 \mu \mathrm{mol} \mathrm{m} \mathrm{m}^{-2}, 2018-2019$ yılı: $71.80 \mu \mathrm{mol} \mathrm{m}{ }^{-2}$ ). 2017-2018 vejetasyon döneminde $\mathrm{F}_{1}$ Kamome Red ile $\mathrm{F}_{1}$ Pigeon Red $\left(56.96 \mu \mathrm{mol} \mathrm{m}{ }^{-2}\right)$ çeşidi arasında istatistiki açıdan bir farklılık bulunmamış olmakla birlikte, en az klorofil içeriğine sahip çeşit, $F_{1}$ Pigeon White $\left(50.05 \mu \mathrm{mol} \mathrm{m} \mathrm{m}^{-2}\right.$ ) olmuştur. 2018-2019 vejetasyon döneminde en az klorofil içeriğine sahip çeşit, $F_{1}$ Kamome White

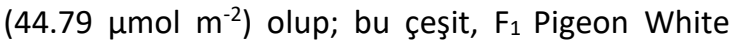


içerisinde yer almıştır. 
Çizelge 8. Hibrit süs lahanası çeşitlerinin vejetasyon dönemlerine ait klorofil içerikleri

\begin{tabular}{|l|c|c|c|}
\hline \multirow{2}{*}{\multicolumn{1}{c|}{ Çeşit }} & \multicolumn{2}{|c|}{ Klorofil içeriği (SPAD- $\mathbf{m m o l ~ m}^{-\mathbf{2}}$ ) } \\
\cline { 2 - 4 } & $\mathbf{2 0 1 7 - 2 0 1 8}$ & $\mathbf{2 0 1 8 - 2 0 1 9}$ & Yıl Ortalaması \\
\hline F1 Pigeon Red & $56.96 \mathrm{ab}$ & $55.64 \mathrm{~b}$ & $56.30 \mathrm{~B}$ \\
\hline F1 Pigeon White & $50.05 \mathrm{c}$ & $44.80 \mathrm{c}$ & $47.43 \mathrm{C}$ \\
\hline F1 Kamome Red & $60.11 \mathrm{a}$ & $71.80 \mathrm{a}$ & $65.96 \mathrm{~A}$ \\
\hline F1 Kamome White & $51.32 \mathrm{bc}$ & $44.79 \mathrm{c}$ & $47.55 \mathrm{C}$ \\
\hline Çeşit Ortalaması & 54.61 & 54.25 & \\
\hline
\end{tabular}

*Aynı harfler ile gösterilen ortalamalar arasındaki farklııı $p \leq 0.05$ düzeyinde önemsizdir.

Her ne kadar interaksiyonun önemli bulunduğu durumlarda faktörleri tek başına değerlendirmek etkin bir yaklaşım olmasa da yıl faktörü dikkate alınmadan yalnız çeşit faktörü bakımından bir değerlendirme yapıldığında; $F_{1}$ Kamome Red $\left(65.96 \mu \mathrm{mol} \mathrm{\textrm {m } ^ { - 2 }}\right.$ ) çeşidinin en fazla klorofil içeriğine sahip olan çeşit olduğu görülmektedir. Bu çeşitten sonra en fazla klorofil içeriğine sahip çeşit $F_{1}$ Pigeon Red $\left(56.30 \mu \mathrm{mol} \mathrm{m}{ }^{-2}\right)$ olmuştur (Çizelge 8).

Çalışmada kullanılan çeşitlere ait klorofil içerikleri genel olarak $44.79 \mu \mathrm{mol} \mathrm{m} \mathrm{m}^{-2}$ ile 71.80 $\mu \mathrm{mol} \mathrm{m}^{-2}$ arasında değişiklik göstermiş olmakla birlikte, Ağar (2015) tarafından farklı yetiştirme ortamlarının iki farklı hibrit süs lahanası çeşidinde kalite parametreleri üzerine etkilerinin incelendiği bir çalışmada klorofil içeriklerinin $46.18 \mu \mathrm{mol} \mathrm{m} \mathrm{m}^{-2}$ ile $65.28 \mu \mathrm{mol} \mathrm{m}{ }^{-2}$ arasında değiştiği, Akın (2019) tarafından saksı kültüründe yetiştirilen bir süs lahanası çeşidinde klorofil içeriklerinin $34.42 \mu \mathrm{mol}$ $\mathrm{m}^{-2}$ ile $47.98 \mu \mathrm{mol} \mathrm{m}{ }^{-2}$ arasında değiştiği ve Eman Gökseven (2019) tarafından örtü altında yetiştirilen bir süs lahanası çeşidinde ise $24.37 \mu \mathrm{mol} \mathrm{m} \mathrm{m}^{-2}$ ile $15.07 \mu \mathrm{mol} \mathrm{m} \mathrm{m}^{-2}$ arasında değiştiği saptanmıştır. Çalışmalar arasında klorofil içeriklerinin farklılık gösteriyor olması, bitkilerin maruz kaldıkları stres koşullarının değişiklik göstermesine bağlı olabilir. Yapraklardaki klorofil miktarının edafik ve klimaktik faktörlerden etkilenerek değişiklik gösterdiği çeşitli araştırmacılar tarafından da belirtilmektedir (Sevik ve ark., 2012; Çetin ve ark., 2018).

Çalışmada kullanılan çeşitler arasında, kırmızı renkli hibrit çeşitlerin klorofil içerikleri; beyaz renkli hibrit çeşitlerden daha yüksek bulunmuştur. Bu durum, yaprak su içeriğinin kırmızı çeşitlerde daha yüksek olmasından ileri geliyor olabilir. Nitekim klorofil içeriği ile yaprak su içeriği arasında önemli bir ilişki bulunduğu ve su içeriği yüksek olan yapraklarda klorofil içeriğinin de daha yüksek olduğunu bildiren çalışmalar bulunmaktadır (Marenco ve ark., 2009; Keskin ve ark., 2017). Bunun yanında, kırmızı hibrit çeşitlerde klorofil içeriğinin yüksek olması antosiyanin pigmentinin varlığı ile ilişkili olabilir. Eryılmaz (2003), artan antosiyanin pigment miktarının, fotosentez olayında metabolik faaliyetler sonucu meydana gelen serbest radikaller ile UV ve diğer çevresel etmenlerin zararlı etkilerini yok ederek klorofil pigmentlerini koruduğunu öne sürmektedir.

\section{Sonuç ve öneriler}

Bazı hibrit süs lahanası çeşitlerinin Yozgat ilii ekolojik koşullarına adaptasyon kabiliyetinin incelendiği bu araştırmada, çeşitler arasında yaprak sayısı ve merkez renklilik çapı bakımından $F_{1}$ Kamome White ve $F_{1}$ Pigeon White çeşitleri; antosiyanin miktarı ve klorofil içeriği bakımından ise $F_{1}$ Kamome Red ve $F_{1}$ Pigeon Red çeşitleri ön plana çıkmıştır. Her ne kadar bazı özellikler bakımından belirli çeşitler ön plana çıkmış olsa da denemede kullanılan tüm süs lahanası çeşitleri, diğer çalışmalar ile karşılaştırıldığında oldukça iyi sonuçlar vermiştir. Bunun yanında, incelenen özellikler arasında çeşitlerin bitkisel tasarımda kullanılabilirliğini olumsuz yönde etkileyebilecek seviyede bir farklılık görülmemiş ya da görsel kalite kaybı söz konusu olmamıştır. Dolayısıyla denemeye alınan çeşitlerin Yozgat ili ekolojik koşullarına uyum sağlayabildikleri ve Yozgat îli ekolojik koşullarının süs lahanası yetiştiriciliği için oldukça uygun olduğu söylenebilir. Ayrıca çalışmada yapılan gözlemler sonucunda kar yükünün bitkilerde görsel kalite kaybına neden olduğu; kıvırcık yapraklı çeşitlerin düz yapraklı çeşitlere oranla daha fazla zararlandığı görülmüştür. Bitkisel tasarım çalışmalarında kar yükünün fazla olduğu bölgelerde düz yapraklı çeşitlerin öncelikli olarak tercih edilmesi gerektiği sonucuna varılmıştır.

Teşekkür: Bu proje, Yozgat Bozok Üniversitesi BAP komisyonu tarafından $6602 \mathrm{~b}-\mathrm{ZF} / 17-88$ proje kodu ile desteklenmiştir.

Çıkar Çatışması Beyanı: Makale yazarları aralarında herhangi bir çıkar çatışması olmadığını beyan ederler.

Araştırmacıların Katkı Oranı Beyan Özeti: Yazarlar makaleye eşit oranda katkı sağlamış olduklarını beyan ederler. 


\section{Kaynaklar}

Anonim, 2020. Yozgat IIl'i uzun yıllar aylık ortalama iklim verileri. Yozgat Meteoroloji il Müdürlüğü, Yozgat.

Ağar, A. 2015. Atık su arıtma çamurunun süs lahanasının gelişimi ve besin elementi içeriği üzerine etkisi. Çukurova Üniversitesi, Fen Bilimleri Enstitüsü, Yüksek Lisans Tezi, 125 sayfa, Adana.

Akın, F. ve Kahraman, Ö. 2018. Atık su arıtma çamurunun süs lahanası yetiştiriciliğinde kullanılabilirliği. Anadolu Tarım Bilimleri Dergisi, 33: 177-183.

Akın, F. 2019. Atık su arıtma çamurunun süs lahanası yetiştiriciliğinde kullanımı. Çanakkale Onsekiz Mart Üniversitesi, Fen Bilimleri Enstitüsü Yüksek Lisans Tezi, 45 sayfa, Çanakkale.

Atabeyoğlu, Ö. ve Bilge, G. 2019. Corylus türlerinin peyzaj tasarım çalışmalarında kullanılabilirliği. Akademik Ziraat Dergisi, 8(Özel sayı): 145-156.

Bazzocchi, R. ve Giorgioni, M.E. 2003. Effects of Prohexadione-Ca, Uniconazole and Paclobutrazol on ornamental kale growth and performance under high temperatures. ACTA Horticulture 614, ISHS.

Carter, K. 2003. Ornamental kale. Center for Landscape and Urban Horticulture. University of California Cooperative Extension Central Coast \& South Region, $4 p$.

Çetin, I.Z., Cesur, A., Keskin, R. ve Akarsu H. 2018. Bazı peyzaj bitkilerinde klorofil miktarının değişimi: Samsun örneği. Kastamonu University Journal of Engineering and Sciences, 4(1): 1-10.

Dela, G., Or, E. Ovadia, R., Nissim-Levi, A., Weiss, D. ve Oren-Shamir, M. 2003. Changes in anthocyanin concentration and composition in 'Jaguar' rose flowers due to transient high-temperature conditions. Plant Science, 164: 333-340.

El-Soda, M., Boer, M.P, Bagheri, H., Hanhart, C.J. ve Koornneef, M. 2014. Genotypeenvironment interactions affecting preflowering physiological and morphological traits of Brassica rapa grown in two watering regimes. Journal of Experimental Botany, 65(2): 697-708.

Eman Gökseven, Ş.B. 2019. Süs lahanasının (Brassica oleraceae var. capitata) topraktaki bor elementinin giderilmesi amacıyla fitoremediasyonda hiper toplayıcı bitki olarak kullanılma potansiyelinin araştırılması. Ankara
Üniversitesi, Fen Bilimleri Enstitüsü Doktora Tezi, 149 sayfa, Ankara.

Gibson, J.L. ve Whipker, B. 2001. Ornamental cabbage and kale cultivar comparison study: growth characteristics and response to daminozide and uniconazole foliar sprays. Hortechnology, 11(3): 376380.

Hatipoglu, A. ve Gülgün B. 1999. Tek Ve Çok Yıllık Mevsimlik Çiçekler, Yayın Yeri:KENT MATBAASI, Basım sayısı:1, Sayfa sayısı:207.

Jin, S., Rahim, A., Afrin, K.S., Park, J., Kang, J. ve Nou, I. 2018. Transcriptome profiling of two contrastingornamental cabbage (Brassica oleracea var. acephala) lines provides insights intopurple and white inner leaf pigmentation. BMC Genomics, 19(797): 21p.

Keskin, M., Arslan, A. ve Bal, B. 2017. Evaluating water content of strawberry leaves using a chrometer and a chlorophyll meter. International Advanced Researches and Engineering Congress, Tam Bildiri Kitabı, 2360-2368.

Kishimoto, K., Maeda, H., Haketa, T. ve OyamaOkubo, N. 2014. Odor components and the control of odor development in ornamental cabbage. The Japanese Society for Horticultural Science, 83(3): 252-258.

Köksal, N., Ağar, A., Yasemin, S. ve Korkmaz, K. 2016. Süs lahanası yetiştiriciliğinde fosfor gübrelemesinin bitki gelişimi ve kaliteye etkileri. Bahçe Dergisi, 45(Özel Sayı): 984988.

Kösa, S. 2019. Antalya Kaleiçi sokaklarının bitki materyali ve bitkisel tasarım açısından değerlendirilmesi. Ege Üniversitesi, Ziraat Fakültesi Dergisi, 56(1): 63-75.

Li, D., Wang, X., Zhang, X., Chen, Q., Xu, G., Xu, D., Wang, C., Liang, Y., Wu, Y., Huang, C., Tian, J., Wu, Y. ve Tian, F. 2016. The genetic architecture of leaf number and its genetic relationship to flowering time in maize. New Phytologist, 210(1): 256-268.

Muntean, D., Munteanu, N. ve Andrieş, I. 2012. Research on main morphological and physiological characters of the species Brassica oleracea var. acephala in Iaşı. Lucrări Ştiinţifice, 55(2): 443-446.

Marenco, R.A., Antezana-Vera, S.A. ve Nascimento, H.C.S. 2009. Relationship between specific leaf area, leaf thickness, leaf water content and SPAD-502 readings in six Amazonian tree species. Photosynthetica, 47 (2): 184-190. 
Onat, i. 2012. İstanbul kenti kamusal yeşil alan düzenlemelerinde mevsimlik çiçek ve soğanlı bitki uygulamalarının irdelenmesi. Bahçeşehir Üniversitesi, Kentsel Sistemler ve Ulaştırma Yönetimi Yüksek Lisans Programı, 156s., İstanbul.

Ren, J., Liu, Z. Chen, W., Xu, H. ve Feng, H. 2019. Anthocyanin degrading and chlorophyll accumulation lead to the formation of bicolor leaf in ornamental kale. International Journal of Molecular Sciences, 20(603): 27p.

Sevik H., Güney D. Karakas H. ve Aktar G. 2012. Change to amount of chlorophyll on leaves depend on insolation in some landscape plants. International Journal of Environmental Sciences, 3(3): 1057-1064.

Sikora, E. ve Bodziarczyk, I. 2012. Composition and antioxidant activity of kale (Brassica oleracea L. var. acephala) raw and cooked. Acta Scientiarum Polonorum Technologia Alimentaria, 11(3): 239-248.

Taş, B. 2000. Toprak ve iklim şartlarına karşı bitkinin genetik adaptasyonu. ANADOLU Journal of the Aegean Agricultural Research Institute, 10(2): 183-189.
Ulukapı, K. ve Şener, S. 2018. Farklı organik gübrelerin tarla ve örtüaltı koşullarında yetiştirilen karnabaharın bitki gelişimi ve verim parametreleri üzerine etkisi. Selcuk Journal of Agriculture and Food Sciences, 32(3): 510-515.

Weishu, C., Yun, Z., Jie, R., Yuying, M., Zhiyong, L. ve Feng, H. 2019. Effects of methylene blue on microspore embryogenesis and plant regeneration in ornamental kale (Brassica oleracea var. acephala). Scientia Horticulturae, 248: 1-7.

Yazici, K. 2017. Kentiçi Yol Bitkilendirmelerinin Fonksiyonel-Estetik Açıdan Değerlendirilmesi ve Mevcut Bitkisel Tasarımların İncelenmesi: Tokat Örneği. Ziraat Mühendisliği, (364), 30-39.

Zhu, P., Tian, Z., Pan, Z. ve Feng, X. 2017. Identification and quantification of anthocyanins in different coloured cultivars of ornamental kale (Brassica oleracea L. var. acephala DC). The Journal of Horticultural Science and Biotechnology, 93(5): 466-473. 